\title{
A STUDY ON THE GAP AREAS IN ECOTOURISM PLANNING, POLICY IMPLICATIONS AND INITIATIVES IN KERALA
}

\author{
Ravish Mathew, * Anu Chandran **
}

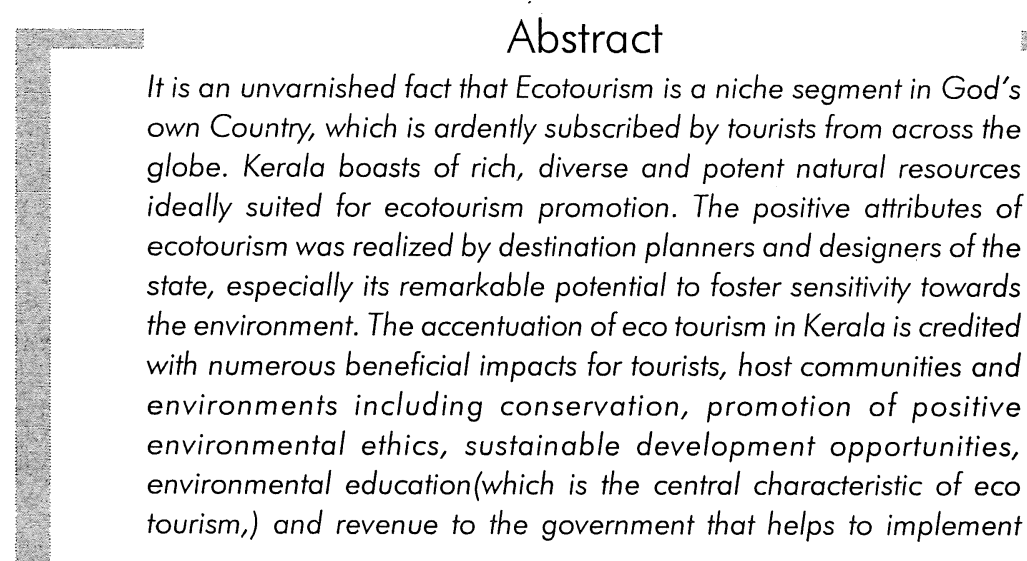

\footnotetext{
* Research Scholar, Department of Tourism Studies, Pondicherry University, Puducherry-605 014
}

** Department of Tourism Studies, Pondicherry University, Puducherry-605 014. 


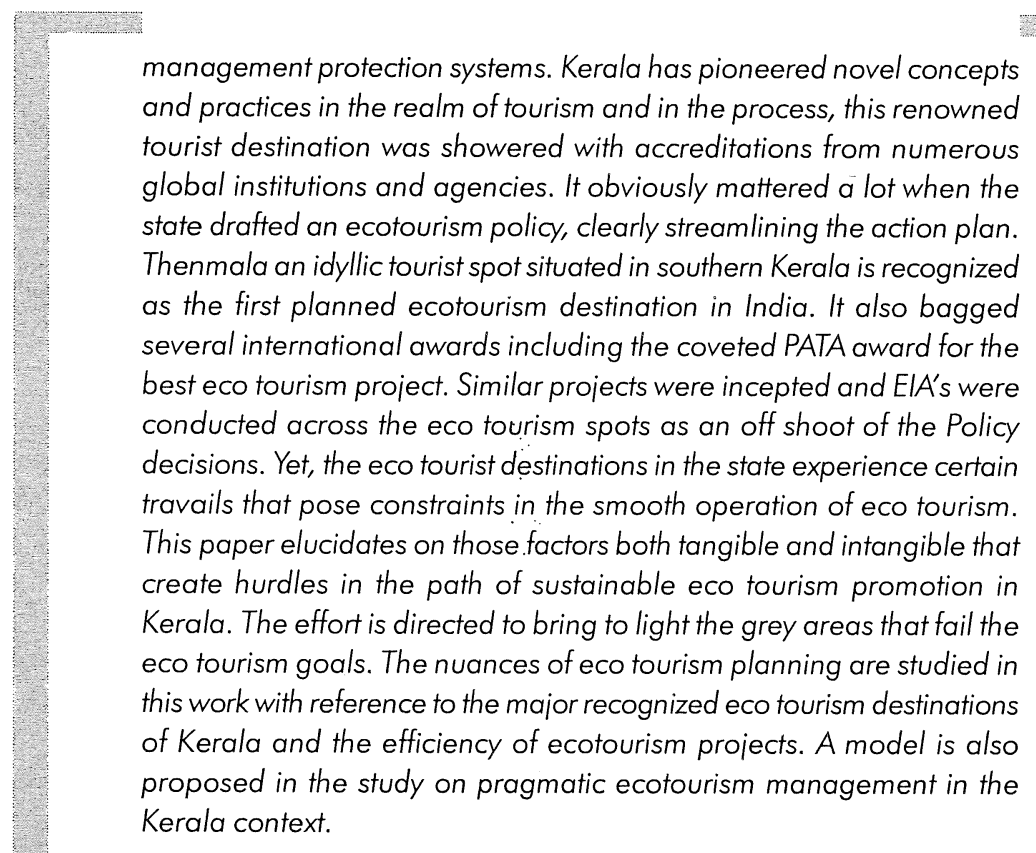

\section{The concept of Ecotourism}

Tourism is currently the world's largest industry and ecotourism represents the fastest growing sector of the market. Ecotourism in simple word means management of tourism and conservation of nature in a way so as to maintain a fine balance between the requirements of tourism and ecology on one hand and the needs of local communities for jobs-new skills, income generating employment and better status for women on the other the global importance of ecotourism, its benefits as well as its impact was recognized with the launching of the year 2002 as the International Year of Ecotourism (IYE), by the UN. Ecotourism has recently come to be regarded as the panacea for damages to ecosystems. Ecotourism has gained momentum in India and slowly it is becoming a way of life. Ecotourism constitutes only a fraction of the broader tourism industry, but many tourists, who would not define themselves as ecotourists, also visit national parks or protected areas as part of their trip. Filion et.al. (1994). Has estimated that tourism in the natural and wild life settings accounted for a total $20-40 \%$ of international tourism receipts, with an estimate that it will increase by 20-50 percent per year. Today the concept of ecotourism has got wide range of acceptability cutting across the boundaries of the country. Ecotourism has become a buzz word and it is in the agenda of discussions 
of governments, industry, and academia and even community circles. With the declaration of 2002 as the International Year of Ecotourism by World Tourism Organization (WTO) it has opened the doors of Wildlife sanctuaries and Protected areas for ecotourism activities with the motive of giving the maximum benefits to the local community. Many researchers have highlighted the positive aspects regarding ecotourism as one of the most sustainable segment. Increased emphasis is being given on the benefits to be accorded to local communities and habitats. The word ecotourism first appeared within the English language academic literature as hyphenated term (ecotourism) in an article by Romeril. According to the researcher Ecotourism is basically one of the forms of responsible tourism and an integral part of sustainable tourism development, which was declared as a global strategy at the world summit at Rio De Janerio in 1992. Kripendrof, (1982) Coined the term Alternative tourism, although the origins of the term "ecotourism "are not entirely clear, one of the first to use it appears to have been Hetzer. Hetzer (1965) who identified the four "pillars" or principles of responsible tourism: minimizing environmental impacts, respecting host cultures, maximizing the benefit of local people, and maximizing tourist satisfaction. Nelson, (1960) the researcher came out with a word called eco-development, low impact, sustainable in nature, community development and moral philosophy levels. The actual term ecotourism was been coined by a Mexican Economist called Ceballos-Lascurine,(1987)Travelling to relatively undisturbed or uncontaminated areas with the specific objective of studying, admiring and enjoying the scenery and its wild plants and animals, as well as any existing cultural manifestation (both past and present) found in these areas. Ziffer, (1989) offered a definition which combined motivation, philosophy, conduct, and economic benefit to conservation. The Eco Tourism Society (1991) defines eco tourism as responsible travel to natural areas which conserves the environment and improves the well being of local people. Further, it is widely accepted that Ecotourism is a non-consumptive activity Mintel, (2004), Reynolds and Braithwaite, (2001). Ecotourism has a greater impact in the rural areas where a large number of tourist, normally spend most of their time with a view to seeking recreation and relaxation. The Canadian Environment Advisory Council (CEAC) has documented the characteristic of modern ecotourism, that, ecotourism is of an enlightening natural travel experience that contribute to conservation of the eco system while respecting the integrity of host community World Wide Fund for Nature (1997). Tourism to protect natural resources, as a means of economic gain through natural resource preservation. As the future of tourism depends on the sustainability attributes, ecotourism has all the qualities to become very popular among the travelers. Mass tourism does irreparable damage to the environment and the flora and fauna in one way or the other. More travelers in future will opt for ecotourism and ecotourism activities. Awareness should be created among the travelers in opting a tour, which is nature-friendly, supporting local communities, their culture, 
traditional ways of life and that which do not exploit them in any way. Thus, ecotourism should be a role model in popularizing responsible tourism and fair business in tourism. Ecotourism being the fastest growing segment of International tourism, it urgently needs proper guidelines and directions of international standards to sustain its natural growth. We can find countries like Costarica and Ecuador; particularly the Galapagos Islands which earned US\$275 and US\$193 million respectively in 1990. Clearly ecotourism becomes the most significant tourism segment for many developing countries. Ecotourism in India if properly implemented can integrate conservation and rural development by helping to protect valuable natural areas by generating income, stimulating economic development through tourism expenditure and market for local goods. The main motive behind ecotourism development is the employment of tourism receipts for the protection of the resources which represents a magnet of tourism and also to provide income by which conservation efforts could be undertaken. Moreover it may justify the USE IT or LOSE IT POLICY as envisaged by IUCN.

\section{Ecotourism in Kerala: Opportunities and Challenges}

Ecotourism is promoted as an ideal concept in God's own country. Ecotourism is of great popularity with the tourists to Kerala because they are instilled with the feeling of oneness with nature. Colorful Kerala is an enchanting kaleidoscope, full of breathtaking surprises. The antiquity of the State can be traced back as early as 5000 to 3000 B.C. The land of lagoons and beaches, Kerala has attracted people and tourists from time immemorial. Kerala is studded with lively palm fringed wide sandy beaches, verdant valleys, limitless stretches of lush vegetation, exotic scenery and above all Kerala unfolds a cultural canvas fascinating in its variety. Kerala reorganized in the present form on $1^{\text {st }}$ November 1956 under the State Reorganization Act 1956, is one of the smallest states of India lying extreme south-west of the subcontinent, bordered by the States of Karnataka on the north, Tamil Nadu on the east and south and washed by the Arabian Sea in the west along a $580 \mathrm{~km}$ long coast line. Kerala has carved a niche for itself in the tourism scenario as a destination of immense natural appeal. Ecotourism is a sustainable management option for all protected areas in Kerala. In spite of all this there are major identified lacunae in information pertaining to Western Ghats monsoon forest in Kerala. (Which is a Hot Spot of Biodiversity) as a popular destination of ecotourism. World Conservation Monitoring centers threatened plant units (TPU) catalogued 150 botanical sites as the world center of plant diversity (IUCN1 987) of the five locations issues for India, of which, the Agasthyamalai Hills, Silent Valley and Periyar National park are from Kerala. The state of Kerala, 'God's Own Country', forming part of the Western Ghats in India contains a protected area of 2,324 square kilometers in four National parks and 12 wildlife Sanctuaries. The Western Ghats of Kerala with its tropical 
forest ecosystem provides a natural advantage for development of Ecotourism. Kerala is thus ideally suited for the promotion of ecotourism and has already initiated several steps in that direction. In Kerala 56 places have been identified for development as ecotourism destinations giving emphasis to conservation, ecological sustainability, environmental education and local benefits. To give fillip to tourism, the Department of Tourism, Govt. of Kerala has set up a separate ecotourism wing to give policy support for the development of ecotourism destinations in the state. The credit goes to Kerala that the first planned ecotourism destination of India is in Kerala (Thenmala) "Then" in local dialect means honey and "Mala" means mountain. In Kerala, the forest and tourism departments have just initiated a process by which all the 12 Wild Life Sanctuaries in the State will be opened for tourism. The Kerala Forest Research Institute (KFRI), meanwhile, has initiated a World Bank funded study aimed at selectively opening some wildlife areas that include the Eravikulam National Park and the Parambikulam and Neyyar Wildlife Sanctuaries. Besides that Kerala has identified and initiated many places from 14 districts, some of major ecotourism destinations like Neyyar, Kulathupuzha, Gavi,Kumarakom, Chinnar, Bhoothankettu, Peechi, Nelliyampathy, Nilambur, Kakkayam, Tholpetti, Pythalmala and Ranipuram. Besides that the role of VSS (Vana Samarakshana Samiti) and EDC (Eco Development Committee) has given a remarkable boost to the ecotourism activities in Kerala.

\section{Policy Implications of Ecotourism Promotion}

Ecotourism is a segment of the state's tourism industry which has embarked on a mercurial growth curve in the last decade owing to its closeness with nature and sustainable activities. The policy makers have taken into account the potential of this form of alternate tourism as it offers tremendous change of experience to the city-bugged and pollution-fatigued tourists. The ramifications of Ecotourism Policy have a pronounced impact in Kerala, occupying a prominent position on the world tourism map. What aspects need to be tapped in the state is aplenty. Land and water share an extraordinary kinship in the state with its lush palm groves, lovely stretches of paddy fields, plenty of swaying coconut trees, exotic backwaters, hills and valleys. The State's Tourism Policy considers ecotourism as something very closely related to nature and which includes in itself a detailed study of the environment apart from maintaining a balance in the ecological system. Furthermore, by attracting domestic and international tourists in large numbers, ecotourism promotion provides more economic benefits to the government and local communities. The concerns addressed in the Policy indicate to the stakeholders in tourism that no development in the realm of ecotourism should disturb the ecological balance of the locality or quality of life of the local population. Also, the directives affirms that all development works should be carried out in an eco- 
friendly manner, with the cooperation of the local people, be it the construction of roads, sewage disposal plants or the provision of water supply. It could be deducted from the policy framework that qualitative tourism is what destination planners are vying for.

The firm recommendations of the Tourism Policy of Kerala emphasize balanced regional development as an aspect in which ecotourism plays an important part. This is mainly because ecotourism activities are planned and managed in ecofriendly places of environmental delight away from overcrowded cities, in suburban and rural areas. The alluring factors of ecotourism lead to development activities ushering in great improvement in the standard of living of the host communities. The Vision statement of Tourism Policy reinforces the role of tourism as a key engine for the creation of large scale employment opportunities, and ecotourism business ventures fits the bill. The measures are upheld keeping in view the welfare of the rural folks.

Studies indicate that excessive and badly planned tourist development affects the physical environment of destinations. Keeping this in view the policy makers have introduced the provision to control commercial exploitation of tourism resources and destinations. For instance, the perpetuation of hotels and resorts, the designs of which are not conforming to the local architecture and which intrudes into the surrounding natural, scenic and cultural environment is staunchly regulated. This is following the realization that proper planning on the architectural design is the need of the hour to save the local environment. It is a common understanding that poor and ill-conceived forms of tourism development also destroy irreplaceable natural resources and the provision of proper evaluation of the true and long term benefits of it is apparently not reflected in the present policy document. For example, the recent issues in Kerala associated with tourism promotion around marshlands and mangrove swamps which provide basic outlets for flood control and also the basic ingredients for local fishing industries necessitates the fine-tuning of certain clauses in the Tourism Policy of Kerala. Setting up of tourist marinas at the cost of depletion of mangroves and farming lands poses danger to the habitats.

It is heartening to note that in the Tourism Policy terms like carrying capacity and sustainable development assumes greater importance. This is utmost essential to address the negative impacts, as in the prominent ecotourism spots of Kerala; especially as regards the scale of development, problems like trampling of fragile flora and vegetation, littering of non bio-degradable wastes, poaching of wild animals, issues associated with congestion, pollution of water bodies, depreciation of forest cover, etc are often cases of deep worry. This study reinforces the fact that there is a cost of intensive development and the authorities and destination designers must see to it that the adverse effects are mitigated to the best possible extent. For 
instance, in some ecotourism locales of Kerala the water resources required by local farmers and villagers have been diverted for the use of resorts, golf courses and hotels. This result in host-guest conflict as such a social encounter involving sharing of vital elementary resources which are scarce, is not easily digestible. Moreover, the depletion of forest cover in the hill stations to construct tourism ventures leads to soil erosion, flooding and mud slips, causing substantial loss of life and damage to property.

The provision for continuous management of ecotourism spots in Kerala is generally felt and the policy framework must cover the key aspects of evaluation and monitoring. Positive checks can go a long way in establishing the ideals of sustainable ecotourism. Tourists as well as promoters sometimes ignorantly, sometimes deliberately damage crops, frighten animals and bestrew large quantities of garbage over the country side. In some sanctuaries and parks of the state, wild life has been severely disturbed and alien forms of plant life have been introduced into delicate ecosystems through the foot wears and clothes of the visitors. These disadvantages could be offset by policy decisions paving the way for high quality planning, design and management and also by educating the tourists to appreciate the environment.

The revised ecotourism policy of Kerala needs to look into effective revenue management as the money spent by tourists for various components at the ecodestinations including entry fees can be used to conserve and improve the natural and man-made heritage. There are awesome tourist spots in Kerala to entice historical and architectural tourists and tourism provides the incentive and helps pay for the conservation of heritage, archaeological and historical sites which otherwise would be allowed to deteriorate or disappear. This can act as a catalyst for countries which have limited resources for archaeological and historic preservation.

The Policy matters are of profound importance not only in the context of ecotourism planning, but also define the role of stakeholders in holistically developing the destination with the concern for sustainability. It is time for Kerala to lay stress on Environment Impact Assessment (EIA) and feasibility studies, researches and analyses to obtain a 360 degree view on the nuances of ecotourism management in the state's ecotourism projects. The Tourism Policy imbibes the extent and nature of the environmental damage caused by tourism in consonance with the magnitude of development and the volume of visitors, the concentration of usage both spatially and temporally, the nature of habitats and the nature of the planning and management practices adopted before and after development. There is obviously a need for research to examine the environmental impact of tourism in Kerala. The policy must urge all stakeholders to develop environmental indicators for use in cost-benefit analysis and also allow environmental standards to be devised at 
ecotourism destinations to support tourists. This is mainly owing to the fact that the relationship between tourism and the environment is mediated by planning and management. The state can always subscribe to the management techniques that prevail and are well tried in many areas. The revised Policy is expected to address and remove the barriers to planning and management to allow the incorporation and effective application of emerging practices and novel techniques. Further, future issues to consider will be the development of financing models to ensure continuity of funding to monitor and maintain the ecotourism projects and also the step up of regulatory measures in potential eco-destinations. The key questions to be considered as part of the policy imperatives are:

- How many and what type of tourists does the resident population of an ecotourism area wish to attract?

- What is the optimum number of tourists that the area can support in terms of its physical, environmental and social carrying capacity?

- How can eco tourists contribute to the improvement of environmental quality and increasing environmental awareness?

The government needs to ensure that planning for the resultant impact necessitates essential co-ordination and a clear cut definition of the responsibilities of the public and private sectors. The government should also promote campaigns for the need to protect the environment through ecotourism as a premier force. The policy experts should lay down norms for disposal of waste water and chemicals from factories and stipulate rules and regulations to grant clearances to ecotourism projects from the environment-friendly angle. Provisions to explore ways on harmonizing tourism and environment-tourism instrumental in contributing to the enhancement of beautycan make Kerala scale even greater heights as an outstanding tourism brand.

Any policy related to sustainable ecotourism programme in Kerala should have the following objective:

- Defining the role of ecotourism in the frame work of a sustainable development strategy for Kerala.

- Reducing the threat posed by uncontrolled tourism development at the fragile sites meant to be considered.

- Developing a source of long term financial sustainability for the conservation of protected area sites.

- Identifying and promoting the best practices. 


\section{Model Suggesting Indicators of Sustainable Ecotourism in Kerala}

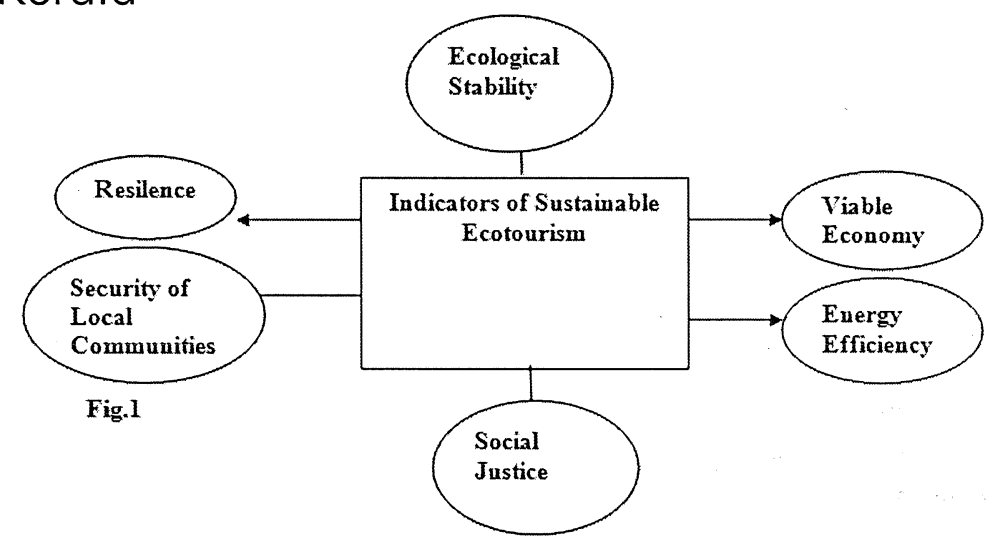

\section{SWOT Analysis}

(Based on literature review and expert opinion)

\begin{tabular}{|c|c|}
\hline STRENGTHS & WEAKNESSES \\
\hline $\begin{array}{l}\text { - Kerala's geography is quite } \\
\text { suitable for ecotourism activities. } \\
\text { - } \quad \text { Rich in flora and fauna } \\
\text { Blessed with miles and miles of } \\
\text { endless serene beaches, tranquil } \\
\text { stretches of emerald backwaters, } \\
\text { pristine valleys and mountains, } \\
\text { exotic species; all together adds } \\
\text { value to the ecotourism } \\
\text { potentiality. } \\
\text { Separate ecotourism wing to give } \\
\text { policy support forthe development } \\
\text { of ecotourism destinations in the } \\
\text { state. } \\
56 \text { ecotourism destinations are } \\
\text { identified as having immense } \\
\text { possibilities for organizing } \\
\text { ecotourism activities. }\end{array}$ & $\begin{array}{l}\text { - Lack of effective community } \\
\text { participation and the awareness } \\
\text { of wholesome benefits } \\
\text { - Lack of pro-active involvement of } \\
\text { rural sector } \\
\text { - Lack of concern of Sustainability } \\
\text { - Degradation of forest and natural } \\
\text { - Infrastructural inadequacy }\end{array}$ \\
\hline
\end{tabular}


- The forms of tourism which could be considered the subsets of ecotourism such as Plantation tourism, farm tourism, country side vacations, Tree houses, etc that takes tourists closer to nature is gaining coinage in Kerala.

- The first planned ecotourism project is credited to Kerala. (Thenmala Ecotourism project)

- Eco-Kerala initiative, Eco-friendly resorts and Eco-Certification scheme for the Hospitality sector.

- Provide adequate incentives for promotion of eco-friendly technologies in tourism sector.

- Sensitivity of operators

- Synergized ventures

- The ideal of qualitative tourism

- The green potential

- Introduce Eco-Certification programmes for all stakeholders in the Tourism Industry.

- Create Awareness

- Appropriate institutional mechanism to provide technical, financial and infrastructural support to agencies that have got ecotourism resources both public and private.

- Private Public Participation in Tourism.

\section{THREATS}

- Neighboring states like Karnataka, Tamil Nadu are doing extremely well with many innovative ideas.

- Many ecotourism destinations are not properly maintained.

- Ecotourism should not be viewed as a mass tourism destination and should be promoted as special interest tourism.

- Lackadaisical approaches of promoters 


\title{
Gap Areas in Eco tourism development in Kerala
}

\author{
A major part of tourists visiting Kerala are visiting the Protected Areas. In Periyar \\ Tiger
}

Reserve alone, more than 2,38,047 tourists visited in 199 1 -92, of which foreign tourists accounted for $8.4 \%$ and it increased to 39,378 foreigners in 2005 and domestic tourist by 47,3772 and 51,025 foreigners in 2008 and 53,1970 domestic tourist and it is predicted to be 6 lakhs by 2010 www.keralatourism.org/ tourismstatistics/tourist-statistic2008 (Manoharan, 1996). Similar high influx of tourists is observed in Vazhachal forests also (Animon et al 1997). But still, the available data is alarmingly inadequate to provide a lucid picture of the ecotourism potential of Protected Areas in Kerala. Due to lack of publicity and proper planning, most of our Protected Areas, which would have become ecotourism hubs, are unnoticed and ignored by the domestic and international tourists. Hence initiatives to develop ecotourism in Protected Areas are the need of the hour. Simultaneously, we may also think of developing some criteria and indicators of ecotourism and a protocol for its monitoring. Environmental Impact Assessment and Carrying Capacity studies are a must for the success of ecotourism. In Sabarimala, forming part of the Periyar Tiger Reserve in Kerala, pilgrimage tourism has exceeded the carrying capacity and has affected detrimentally the species composition and structure of flora and distribution of fauna Animon, (2001). Traces of plastics deposited by the pilgrims were commonly detected in the droppings of wildlife (Animon, 2002). The negative impacts of unscientifically planned ecotourism on wildlife and their distribution pattern in Vazhachal Forest Division was reported by Animon (1996). The shortterm financial gains outweigh the long-term benefits of conservation. Economic justifications warranted to convince policy makers about economic viability of Protected Areas for making unbiased decisions with respect to developmental projects. Preliminary studies in this aspect have been initiated in Periyar Tiger Reserve (Manoharan, 1996). George (2000) estimated the ecotourism value of PeechiVazhani Wildlife Sanctuary. Several concepts like green accounting and international pricing are emerging in the field of ecological economics, which may be applied in our Protected Areas also. Need of the hour is to perform Zonation in Protected Areas in Kerala for better planning and implementation of different components of ecotourism. Site-specific Action Plan may be formulated for ecotourism development and thereby enable pumping of "tourism dollars" to alleviate chronic problems like under budgeting and understaffing of Protected Areas. Reliable estimates of carrying capacity shall be worked out and Environment Impact Assessment may be done in all the Protected Areas so as to avoid the ill effects on tourism. Also, total economic valuation of Protected Areas may be attempted in order to justify conservation and to avoid biased decisions with respect to development and to prioritize conservation 
strategies based on importance. It is also a prerequisite to develop monitoring mechanisms as well as criteria and indicators for sustainable use of Protected Areas through ecotourism. There are many road blocks in ecotourism promotion such as lack of community participation, lack of involvement of rural sector and lack of concern of sustainability. Today we find all the ecotourism destinations are becoming mass tourism destinations and there is no proper carrying capacity check its perpetuation. Ecotourism activities should be special interest tourism specially confined and ear marked to researchers, wildlife enthusiasts and ecotourists, Special interest tourists, Biologists etc. It should be considered as a niche segment. It was realized during the study that the synergized ventures between the Tourism Department and private entrepreneurs and tour operators hold the key for ecotourism development in the state. In this context, it is paradoxical that tour operators, especially those dealing with ecopackages are not given sufficient guidance and motivation to sensibly conduct package eco-tours to the spectacular eco-destinations. Another related aspect is that the involvement of NGO's in the management of ecodestinations of Kerala has unfortunately not risen to the expectations. The drive to sensitize the local people to carry out their daily activities and also to work in an eco-friendly manner has not been undertaken in a continuous fashion. It need to be ensured that all the activities involving natural wealth should be undertaken with the co-operation of the concerned authorities, be it construction of roads and resorts, drainage system and supply of water. The tourism department can always rope in $M N C^{\prime}$ s and other big companies to patronize eco-projects as part of their Corporate Social Responsibility. In the course of dynamic ecotourism development, both the ecological security of the state and livelihood security of the communities have to be definitely taken in to account keeping in view its high dependence on biodiversity and natural resources. Hence the technical execution of eco-projects has to be spotless. The portrayal of a comprehensive picture of biodiversity conservation through "peoples plan" will hopefully make the critical difference. It is a fact that there is a dire need for the continuous management of the environmental resources for tourism in Kerala. The Policy makers have to deal with maintenance, and, where necessary improvement of the overall environmental quality of ecotourism areas for the benefit of both tourists and residents. "Soft Tourism" is the concern in the perspective of ecotourism promotion. As it is now possible to systematically evaluate the various impacts and recommend ways to mitigate them, preferably through measures of environmental planning and engineering and also by applying remedial measures to solve the mistakes already made, the public sector can capitalize on that for accomplishing the best in the realm of eco and nature based tourism in Kerala. However, there is a need for continuing research, especially on the environmental impacts of tourism development in the ecologically sensitive and vulnerable areas of Kerala. Deforestation, enormous waste generation and cultural pollution are the major ill effects raised by the host population of eco-destinations 
of Kerala. It is a fact worth mentioning that there should be positive checks on whether the projects abide by the EIA (Environmental Impact Assessment) under the Environmental Protection Act. The projects are to be given licenses only after obtaining environmental clearance from the concerned agencies. The investors must be directed to follow the CRZ (Coastal Regulation Zone) norms.

\section{Proposed Model of Ecotourism Development and Management in Kerala}

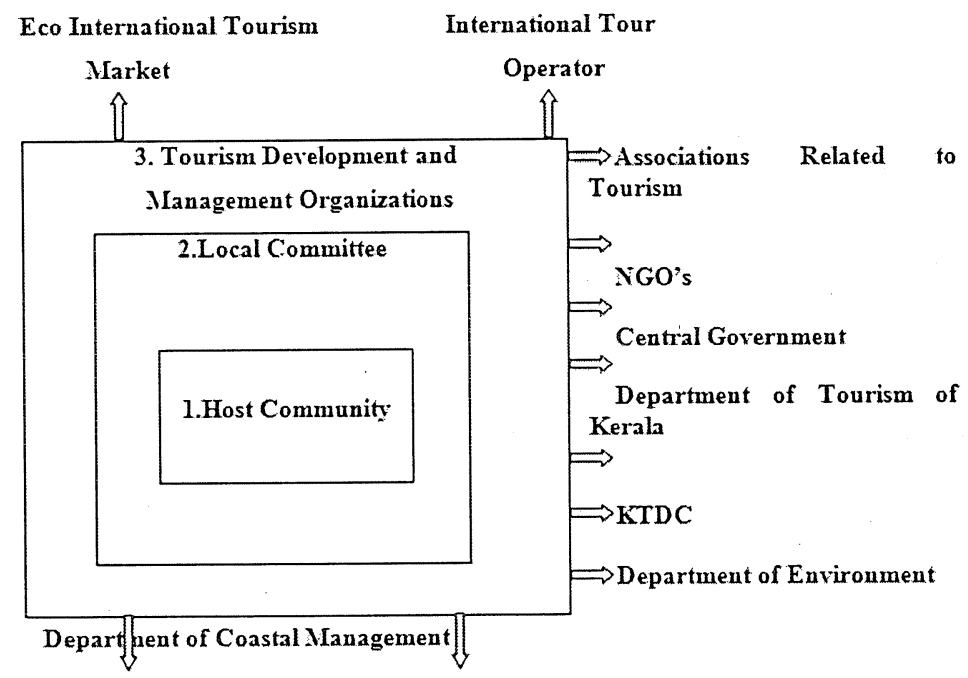

Local Tourist

Local Tour Operator

Fig. 2

\section{Case Study}

\section{The Dynamics of Ecotourism Promotion in Gavi}

The Ecotourism project situated on the buffer zone periphery of the Periyar Tiger Reserve has caught the attention of both domestic and international tourists alike. This project is called Gavi Eco Project; which entices lot of nature enthusiasts, wildlife lovers, Bird watchers and researchers. Gavi is a part of Ranny Perunad Panchayat of Ranny taluk in Pathanamthitta district of Kerala. This Picturesque 
village located about $18 \mathrm{Kms}$ from Periyar Wildlife Sanctuary at Thekkady is an offbeat destination. Notably, Gavi is the home to mega fauna including Tiger, Leopard, Elephant and Gaur. Significantly the forest here also support wild life that is unique to the Western Ghats including the endangered Lion tailed Macaque, Brown Palm Civet, Brown Mongoose and Nilgiri Marten. Gavi's bird diversity is fabulous too- out of 484 species of birds found in Kerala 260 species are found in Gavi and this was one of the places which was identified by the famous ornithologist Salim Ali for bird watching. This spectacular ecotourism haven offers the opportunity of camping in the wilderness - a rarity in wildlife areas throughout India. Gavi is indeed one of the must see places that has been developed in to an ecotourism destination. The sprawling grasslands, tropical forest, cascading waterfalls and cardamom plantation make Gavi one of its kinds in the whole country. Entry to Gavi is regulated and the tourists need to obtain pass from the check post from Vandiperiyar, Vallakkadavu range. Green Mansion run by the Kerala Forest Development Corporation offers lodging in Gavi. There is a sizable population of Tamil settled in Gavi. The youth are employed as guides, workers, drivers, and tour coordinators at Gavi Eco Project. The tree top houses at Gavi provide a unique experience to the visitors. A movement of community led ecotourism activities can be extremely beneficial to Gavi.

\section{Findings and Suggestions}

- Awareness among tourists and local tour operators engaged in sensitive ecotourism spots of Kerala can be generated through efforts like ecoguide training programme, green certification, sensitizing campaigns, etc.

- Formation of self help groups is ideal in Kerala keeping in view the attributes of ecotourism.

- Ecotourism fosters community empowerment.

- Ecotourism enhances quality of life of residents.

- Promotion of ecotourism leads to careful usage of water, power and land.

- There is immense scope for consumption of local products owing to the development of ecotourism.

- Economic growth lead to revenue generation for protected areas in Kerala.

- The importance of upgrading service quality in ecotourism ventures is of profound significance. 
- Leisure patterns of tourists to God's own Country are changing with the proliferation of ecotourism activities.

- Women and Youth participation in ecotourism and development in Kerala can initiate outstanding results.

- The local population started identifying themselves with the eco development initiatives that offset Xenophobia.

- Ecotourism promotion supports Bio-diversity conservation and Sustainable development in Kerala.

- Accreditation for ecotourism projects need to be made mandatory.

- Continuous monitoring and evaluation is utmost required for ecotourism ventures.

- Innovative and creative projects like Ecotel's have to be set up in Kerala.

- Product positioning is very significant in ecotourism marketing in Kerala.

- Ecotourism in the state has to operate under certain prescribed codes of conduct.

- Ethical ecotourism promotion is the need of the hour.

- All efforts by stakeholders must be to synthesis theory and practice.

- In certain ecospots like Ponmudi near Thiruvananthapuram authorities have to look in to certain well established restructuring processes and attempts to develop sustainable agendas.

\section{Conclusion}

In the present day terms like carrying capacity, positive checks, responsible tourism and sustainable development assume greater importance in ecotourism promotion. To realize potential of ecotourism as a tool for conservation and economic development, new and more integrated approaches are essential which place greater emphasis on building local capacity and enhancing local benefits. There is a need to develop appropriate models for infrastructure development; frame works to guide tour operators, NGO's Partnerships; effective training programmes for local nature guides; and methods and skills for participatory, community based ecotourism planning and development etc. Planning of an ecotourism policy in their macro, meso and micro dimensions should give utmost importance for the empowerment of the local communities. The planning and development of ecotourism infrastructure 
in Kerala, its subsequent operation and its marketing should focus on environment, social, cultural and economic sustainability criteria. It is paradoxical that for most protected areas and surrounding communities in the ecospots of Kerala, ecotourism remains an unrealized possibility and the links between ecotourism development and conservation are poorly understood. The authorities must realize that the tendency for international technical assistance patronization and institutional support to substitute for local capacity hinders development rather than to foster it. In Kerala, protected areas promoters and local communities are struggling to balance the need for economic growth with the preservation of natural resources. Ecotourism is most certainly to offer one way of striking the balance. The strong orientation of ecotourism towards principles, guidelines, assessment and certification based on sustainability standards gives it a unique position in the tourism sector of the state. Ecotourism in Kerala is facing various challenges due to the lack of strategic business plans, lack of well planned, local nature guides, lack of sustainable marketing technique, (both for tourism and indigenous people) lack of methods for gaining community consensus on development projects and lack of infrastructure, etc. To address the challenges mentioned above, guidelines on ecotourism planning, feasibility, evaluation, and appropriate business planning have to be developed by Policy makers at various levels. NGO's based in the state could also influence the ecotourism policy. Guidelines for facilitating greater community participation in planning and managing ecotourism in Kerala should be promoted along with developing a methodology for monitoring impacts of ecotourism; to control them. Kerala has a huge potential to be developed as a world class ecotourism destination. Kerala is the first state to promote ecotourism in a much bigger way. 56 destinations have been identified by forest Department of Kerala for promotion of ecotourism in a much bigger way. The public private partnership is also envisaged. The ecotourism products developed by the Forest Department and VSS can be marketed with Government and private sector support. The institution of VSS (Vana Samrakshana Samiti) in ecotourism is a novel concept, which ensures that the local communities get benefited from ecotourism. It is the local people who organize the ecotourism programmes with technical assistance from Forest Department. Apart from providing financial benefits, this will also empower the local population. The Western Ghats of Kerala with its tropical forest ecosystem provides a natural advantage for development of ecotourism. Western Ghat regions of Kerala can be projected as an ecotourism zone in its true sense. Major Ecotourism resources of Kerala are 15 Wildlife Sanctuaries, 5 National Parks, several scenic mountainous regions, estuarine ecosystems, fresh water lakes, mangroves etc. Kerala as an awesome ecotourism destination should give emphasis to conservation, ecological sustainability, environmental education and local community benefits and should be managed in a sustainable manner so that the pristine beauty can be protected and preserved for the future generation. 


\section{References}

Animon, M.M.(1996) Habitat utilization of animals and their parasitic burden with special reference to elephants in Vazhachal Forest Division, Kerala, India. M.Sc. Forestry Thesis. College of Forestry.

Animon, et.al (1997) Ecotourism as a sustainable way of conservation of natural resourcesExperiences from Vazachal Forest Division. Abst. Proc.National Symp.Nat.Resource Mnage.Trichy:76.

Animon, M.M (2001) Comparison of Savanna grassland and similar habitats converted with Eucalyptus in Periyar Tiger Reserve, Research Report, Kerala Forest Department, and Thekkady.p50.

Animon, M.M (2002) Phytosociological studies of Poongavanam area of Periyar Tiger Reserve, Research Report, Kerala Forest Department, Thekkady, p80.

Boo, E. (1991) Ecotourism: A tool for conservation and development. In J. A Kusler (Complier) Ecotourism and Resource Conservation: A Collection of Papers (Nol.1) (pp.54-60). Madison: Omnipress.

Boo, E (1991) Planning for ecotourism. Parks 2(3),4-8.

Ceballos-Lascurine, H (1987) The future of ecotourism. Mexican Journal (January), 13-14.

Filion, F.L, (1994) The economics of global ecotourism. In M. Munasinghe and J McNeely (eds) Protected Area Economics and Policy Linking Conservation and Sustainable Development pp 235-252 Washington, DC: World Bank.

George, B (2000) Ecotourism Value of Peechi- Vazhani Wildlife Sanctuary ,Bsc Forestry Project Report, Kerala Forest Department, Thekkady.p.80.

Orams, M.B.(1995a) Towards a more desirable form of ecotourism. Tourism Management 16 (1), 3-8.

Ravindranathan (2004) Protecting Environment at Sabarimala, Kerala Calling pp29-31.

Yuan .etal (2004) The Prospects of Wildlife Tourism, Journal of Forestry Research, Vol (15)3,pp 243-245.

Ziffer, K.A. (1989) Ecotourism: The Uneasy Alliance. Washington, DC: Conservation International and Ernst and Young

\section{Websites}

http://www.keralaforest.org/htm/general/threats.htm

http://www.eravikulam.org/managementplan.htm

http://www.ecotourism .org

http://www.keralatourism.org

http://www.ecotourismsociety of india.org

http://www.iucn.org 